\title{
Use of chromatin immunoprecipitation (ChIP) to detect transcription factor binding to highly homologous promoters in chromatin isolated from unstimulated and activated primary human B cells
}

\author{
Rebecca L. Dryer ${ }^{1}$ and Lori R. Covey ${ }^{\star \star}$ \\ ${ }^{1}$ Department of Cell Biology and Neuroscience, Rutgers, The State University of New Jersey, Piscataway, New Jersey 08854, USA. \\ *Corresponding Author: Lori R. Covey, Department of Cell Biology and Neuroscience, Rutgers, The State University of New Jersey, Piscataway, New Jersey \\ 08854, USA. Email: covey@biology.rutgers.edu
}

Submitted: January 5, 2006; Revised: March 28, 2006; Accepted: March 29, 2006.

Indexing terms: Gene Expression Regulation; Transcription Factors; Chromatin Immunoprecipitation; B cells.

\begin{abstract}
The Chromatin Immunoprecipiation (ChIP) provides a powerful technique for identifying the in vivo association of transcription factors with regulatory elements. However, obtaining meaningful information for promoter interactions is extremely challenging when the promoter is a member of a class of highly homologous elements. Use of PCR primers with small numbers of mutations can limit cross-hybridization with non-targeted sequences and distinguish a pattern of binding for factors with the regulatory element of interest. In this report, we demonstrate the selective in vivo association of NF- $\mathrm{KB}, \mathrm{p} 300$ and CREB with the human $\mathrm{I} \gamma 1$ promoter located in the intronic region upstream of the $\mathrm{C} \gamma 1$ exons in the immunoglobulin heavy chain locus. These methods have the ability to extend ChIP analysis to promoters with a high degree of homology.
\end{abstract}

\section{INTRODUCTION}

The association of cellular proteins with chromatin can elicit a range of cellular responses involving transcriptional modulations, initiation or attenuation of DNA replication and in specific cases, the induction of non-homologous recombination during lymphocyte development and activation. The Chromatin Immunoprecipitation (ChIP) assay has proved to be an invaluable tool for identifying transcription factors associated with promoters at distinct stages of gene activation. This assay, for the most part, has refined in vitro and transfection studies that evaluate the capacity of a distinct factor to bind an identified sequence within a known promoter by demonstrating an in vivo association with the same binding site in chromatin reviewed in $(1,2)$. Accordingly, promoters that have the appropriate factor binding sites may be restricted, via chromatin organization, from interacting with a transcription factor under specific cellular conditions.
In a humoral immune response, multiple genes go through a cycle of transcriptional activation and attenuation in the course of $B$ cell differentiation into antibody-producing cells (reviewed in $(3,4)$. A critical set of genes known to be directly regulated by activation signals at the transcriptional level are the immunoglobulin (Ig) constant region genes within the Ig heavy chain $\left(\mathrm{C}_{\mathrm{H}}\right)$ locus. In the human, there are nine Ig heavy chain constant region genes, $\mathrm{C} \mu, \mathrm{C} \delta, \mathrm{C} \gamma 1, \mathrm{C} \gamma 2$, $C \gamma 3, C \gamma 4, C \alpha 1, C \alpha 2$ and $C \varepsilon$, that encode the heavy chain polypeptides for the $\operatorname{IgM}, \operatorname{IgD}, \operatorname{IgG} 1-4, \operatorname{Ig} A_{1-2}$ and $\operatorname{IgE}$ antibodies, respectively. The $\mathrm{C} \gamma, \mathrm{C} \alpha$ and $\mathrm{C} \varepsilon$ heavy chains are generated via class switch recombination (CSR) after antigen and / or T cell stimulation and thus contribute to the antibody diversity required for a comprehensive humoral response (reviewed in (3)). Upon B cell activation and prior to undergoing CSR, this group of genes becomes transcriptionally active due to the presence of intronic, or I region promoters located upstream of the different $\mathrm{CH}$ exons. The I region 
promoters within a subclass are highly homologous, yet have unique responses to diverse stimuli and thus transcriptional activation of the different I region promoters can greatly influence the antibody profile of a specific response (5-11).

Our laboratory's focus has been to understand the basis for $I \gamma$ promoter activity in response to signals through the CD40 pathway (12-14). This pathway is triggered by cognate interactions with CD40 ligand (CD40L or CD154) expressed on activated $\mathrm{CD} 4^{+} \mathrm{T}$ cells and has been shown

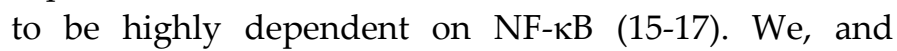
others, have observed that the different $\mathrm{I} \gamma$ promoters respond distinctly differently to CD40 signals both in $B$ cell lines and in primary human B cells $(12,18-20)$. In particular, there is a very strong $\mathrm{I} \gamma 1$ transcriptional response and a very restricted $I \gamma 4$ response. $I \gamma 3$ and $I \gamma 2$ promoters give variable responses depending on the cell line and stimulus. These observations are unexpected given the fact that the proximal promoters are approximately $97 \%$ identical within the subclass. We have analyzed the different $\mathrm{I} \gamma$ promoters in transfection and reporter assays and found discrete differences in transcriptional responses that are sequence-specific (13). In particular, we identified a 36bp region in the $\mathrm{I} \gamma 1$ promoter that contained CREB/ATF binding sites and an adjacent putative NF- $\kappa \mathrm{B}$ binding site ( $\kappa \mathrm{B} 6$ site) that was absent in the $\mathrm{I} \gamma 3$ promoter. We previously demonstrated that the CREB/ATF binding sites function as an "amplifier" element such that its insertion into the $\mathrm{I} \gamma 3$ promoter induces a response greater than that seen with the $\mathrm{I} \gamma 3$ promoter alone (13). Our recent work extended this finding and demonstrated a critical role for the NF$\kappa \mathrm{B}$ site in $\mathrm{I} \gamma 1$ promoter activity in the Ramos B cell line (14). Taken together, our transfection and reporter data revealed important differences in $\mathrm{I} \gamma$ promoter responses to CD40 signaling, however it was evident from the different responses obtained with the reporter constructs compared to the endogenous promoters, that a major form of $\mathrm{I} \gamma$ promoter regulation was at the chromatin level.

Our recent experimental goal focused on determining whether binding at the different $\kappa B$ sites in the $I \gamma 1$ promoter was critical for in vivo expression. Also, we wished to determine whether the interaction between $\mathrm{NF}-\kappa \mathrm{B}$ binding at the $\kappa \mathrm{B} 6$ site, with proteins bound at the adjacent CREB/ATF site and/or upstream $\kappa B 3-5$ sites, was necessary for $\mathrm{I} \gamma 1$ expression in both Ramos B cells and as an extension, primary B cells. In order to study the CD40 regulation of $\mathrm{I} \gamma 1$ transcription at the chromatin level several obstacles had to be overcome. First, it was clear that ChIP assays would give the most accurate pattern of both NF- $\mathrm{kB}$ and co-activator binding in the $\mathrm{I} \gamma 1$ promoter, however these experiments have inherent problems that needed to be solved empirically. Second, only a small number of cells in the Ramos B cell line actually respond to exogenous signals and express $I \gamma$ transcripts, thus in order to obtain meaningful results, we had to use peripheral B cells from isolated blood for our ChIP studies. Finally, we had to utilize PCR protocols that would distinguish the $\mathrm{I} \gamma 1$ promoter from the other three highly homologous $\mathrm{I} \gamma$ subclass promoters in order to be able to convincingly ascribe binding to the I $\gamma 1$ promoter. Here, we describe, in-depth, our methods for identifying the in vivo association of specific transcription factors with a single promoter region that is highly homologous to three other promoters. Furthermore, we outline our procedure for carrying out ChIP on primary human B cells.

\section{MATERIALS AND METHODS}

\section{Isolation and activation of human $\mathrm{CD}_{19}{ }^{+} \mathrm{B}$ cells}

Blood products were prepared by the NBAH Blood Center at Robert Wood Johnson University Medical Center or the New York Blood Center from peripheral blood samples healthy donors. Mononuclear cells (PBMCs) were separated by Ficoll-Hypaque gradient centrifugation. Blood products were diluted 1:1 in RPMI 1640 media layered over Ficoll-Hypaque, and spun for 30 min at 2000 RPM. Buffy coat (the leukocyte layer) was aspirated from the gradient and washed for $30 \mathrm{~min}$ at 1500 RPM in RPMI 1640 media. Total leukocytes were resuspended in 1X PBS containing $2 \%$ FBS and B cells were removed via biomagnetic separation by incubating for $1 \mathrm{hr}$ at $4^{\circ} \mathrm{C}$ with anti-CD19-conjugated superparamagnetic beads provided by Dynal (Lake Success, NY). Beads were washed five times with 1X PBS containing $0.1 \%$ BSA to remove non-specifically bound cells, and plated in $10 \mathrm{mls}$ RPMI 1640 media supplemented with $10 \%$ heat inactivated fetal calf serum (FCS), 50U/ml penicillin, $50 \mu \mathrm{g} / \mathrm{ml}$ streptomycin and $1 \mathrm{mM}$ L-glutamine at $37^{\circ} \mathrm{C} / 5 \% \mathrm{CO}_{2}$ for $12 \mathrm{hr}$. Media was collected and cells were detached from beads using $30 \mu \mathrm{l}$

Dryer \& Covey - Use of chromatin immunoprecipitation (ChIP) to detect transcription factor binding to highly homologous promoters in chromatin isolated from unstimulated and activated primary human B cells www.biologicalprocedures.com 
Dynal anti-CD19 DETACHabead (diluted 100-fold in RPMI containing $1 \% \mathrm{FBS}$ ) for $30 \mathrm{~min}$ at $25^{\circ} \mathrm{C}$. Beads were washed and the supernatant containing $\mathrm{CD} 19^{+} \mathrm{B}$ cells was collected. To deplete the population of "activated" B cells, $\mathrm{IgG}^{+} \mathrm{B}$ cells were removed from the total $\mathrm{CD} 19^{+} \mathrm{B}$ cell population by negative selection. Specifically, antiIgG coated $100 \mathrm{mM}$ plates were prepared with $5 \mathrm{mls}$ coating buffer $(0.5 \mathrm{M}$ Tris- $\mathrm{Cl} \mathrm{pH} 9.5,0.15 \mathrm{M} \mathrm{NaCl})$ containing $25 \mathrm{~g} / \mathrm{ml}$ human anti-IgG (catalog \# 2040-07, Southern Biotech) overnight at $4^{\circ} \mathrm{C}$. CD19+ $\mathrm{B}$ cells from multiple units (up to $1 \times 10^{8}$ cells) were pooled and plated in $10 \mathrm{mls}$ of complete RPMI media, on the antiIgG coated petri dishes for $30 \mathrm{~min}$ at $25^{\circ} \mathrm{C}$. Following incubation, IgG- B cells were analyzed by flow cytometry to verify the success of the isolation procedure.

\section{Flow cytometry}

To analyze lymphocyte populations relative to purity at different stages of the isolation procedure, cells were incubated with specific antibodies and surface expression monitored by flow cytometry. Specifically, $1 \mathrm{x}$ $10^{5} \mathrm{~B}$ cells were washed in $3 \% \mathrm{FCS} / 0.1 \% \mathrm{NaN}_{3} / 1 \mathrm{X}$ PBS followed by incubation for $10 \mathrm{~min}$ at $4^{\circ} \mathrm{C}$ with $5 \mathrm{~g}$ heat aggregated IgG to inhibit non-specific binding. Cells were incubated for $45 \mathrm{~min}$ at $4^{\circ} \mathrm{C}$ with saturating amounts of fluorescein isothiocyanated (FITC)conjugated or biotin-conjugated $\mathrm{mAbs}$ against human CD20 (cat\# 169-020) using $80 \mu \mathrm{l}$ of $10 \mu \mathrm{g} / \mathrm{ml}$ (Ancell, Bayport MN) IgM (cat\# 9020-08) using $80 \mu \mathrm{l}$ of $20 \mu \mathrm{g} / \mathrm{ml}$, $\operatorname{IgD}$ (cat\# 2030-02) using $80 \mu \mathrm{l}$ of $10 \mu \mathrm{g} / \mathrm{ml}$, or IgG (cat\# 2040-01) using $80 \mu \mathrm{l}$ of $20 \mu \mathrm{g} / \mathrm{ml}$ (Southern Biotechnology Associates, Birmingham, AL). Biotin-conjugated samples were further incubated with phycoerythrin-conjugated streptavidin (cat\# 253-050) using $20 \mu \mathrm{l}$ of a 1:10 dilution for $45 \mathrm{~min}$ at $4^{\circ} \mathrm{C}$. Cells were washed and fixed with 500 $\mu \mathrm{l}$ of $1 \%$ paraformaldehyde in 1X PBS. Cells were analyzed using FACScan (Becton Dickinson, Mountain View, CA).

\section{Primary B cell stimulation}

The total population of $\mathrm{CD}^{2} 9^{+} / \mathrm{IgG}-\mathrm{B}$ cells collected from blood isolations were divided equally and plated in 2-5 $\mathrm{ml}$ of complete RPMI in a 6-well dish. The volume of media used for cultures was determined by the number of cells obtained with each isolation, with a final concentration of approximately $1 \times 10^{7} / \mathrm{ml}$. Cultures were either unstimulated or supplemented with $0.5 \mu \mathrm{g} / \mathrm{ml}$ of sCD40L for $2 \mathrm{hr}$, and harvested for chromatin immnoprecipitation assays. To obtain sufficient CD19+/IgG- B cells for chromatin immunoprecipitations, multiple blood isolations were performed and the CD19 $/$ IgG-B cells were pooled. In the event that multiple blood units could not be obtained from blood sources within a $24 \mathrm{hr}$ period, individual blood units were processed. Isolated CD19+/IgG- B cells were stimulated as described above, harvested for formaldehyde crosslinking, and snap-frozen after washing with PBS. To continue with chromatin immunoprecipitation assays, these cell pellets were thawed and pooled to obtain a final cell number of $5 \times 10^{7}$ primary $\mathrm{B}$ cells per experiment.

\section{EMSA to confirm B cell activation}

To determine whether the stimulation conditions were sufficient for primary B cell activation, $5 \times 10^{6}$ primary $\mathrm{IgM}^{+} / \mathrm{IgG}-\mathrm{B}$ cells were removed from culture at $2 \mathrm{hr}$ and prepared for nuclear extracts using a modification of Dignam's method (21). Cells were washed once in 1X PBS, and resuspended in $400 \mu \mathrm{l}$ ice-cold buffer A (10 mM Hepes, pH 7.9, $10 \mathrm{mM} \mathrm{KCl}, 0.1 \mathrm{mM}$ EDTA, $0.1 \mathrm{mM}$ EGTA, 1 mM DTT, 0.5 mM PMSF, $2 \mu$ M aprotinin, $2 \mu \mathrm{M}$ pepstatin A). After incubation on ice for $10 \mathrm{~min}$ NP-40 was added to a final concentration of $0.6 \%$, and nuclei isolated by centrifugation at $14,000 \mathrm{rpm}$ for $30 \mathrm{~s}$. Nuclei were resuspended in $50 \mu \mathrm{l}$ ice- cold buffer $\mathrm{C}(20 \mathrm{mM}$ Hepes, pH 7.9, 0.4 M NaCl, 1 mM EDTA, 1 mM EGTA, 1 mM DTT, $0.5 \mathrm{mM}$ PMSF, $2 \mu \mathrm{M}$ aprotinin, $2 \mu \mathrm{M}$ pepstatin A). Samples were kept on ice for $30 \mathrm{~min}$, with brief vortexing every $5 \mathrm{~min}$ and centrifuged at 14,000 rpm for $10 \mathrm{~min}$. Protein concentration was determined using the Bradford Assay (BioRad).

CD40 signaling in B cells results in an influx of NF- $\mathrm{KB}$ into the nucleus upon activation, therefore the nuclear extracts were incubated with a double-stranded NF- $\mathrm{\kappa B}$ 5'agt tga ggg gac ttt ccc agg c $3^{\prime}$ competitor consensus DNA fragment purchased from Promega Corporation and end labeled with $[\gamma-32 \mathrm{P}]$ ATP, to visualize activation of NF- $\kappa \mathrm{B}$. Binding reactions were prepared using $4 \mu \mathrm{g}$ extract, $1 \mu \mathrm{g}$ poly dI-dC in binding buffer $(10 \mathrm{mM}$ Tris $\mathrm{Cl}$ $\mathrm{pH} 7.5,50 \mathrm{mM} \mathrm{NaCl}, 1 \mathrm{mM}$ DTT, $1 \mathrm{mM}$ EDTA, 5\% glycerol). 3-4 $\times 10^{4} \mathrm{cpm}$ was added to reactions and incubated $20 \mathrm{~min}$ at $25^{\circ} \mathrm{C}$. In order to confirm the 
presence of NF- $\mathrm{KB}$, a supershift assay was performed using $1 \mu \mathrm{l}$ of anti-p50 sera (gift of Dr. N. Rice, National Cancer Institute, Bethesda, MD), and incubating the above mix an additional $1.5 \mathrm{~h}$ at $25^{\circ} \mathrm{C}$ prior to addition of the probe. Samples were loaded on a $6 \%$ acrylamide gel and visualized by autoradiography.

\section{ChIP assay using $\mathrm{CD}^{+}{ }^{+} \mathrm{B}$ cells}

The chromatin immunoprecipitation (ChIP) assay that we devised for our work was an extension of previous protocols $(22,23)$ with some specific modifications. Briefly, $5 \times 10^{7}$ primary B cell cultures were harvested and diluted to $100 \mathrm{ml}$ with $37^{\circ} \mathrm{C}$ media and cross-linked by the addition of one-tenth volume of $11 \%$ formaldehyde in $0.1 \mathrm{M} \mathrm{NaCl}, 1 \mathrm{mM}$ EDTA, $0.5 \mathrm{mM}$ EGTA and $50 \mathrm{mM}$ Hepes, $\mathrm{pH} 8.0$ in growth medium for $5 \mathrm{~min}$ at RT, before addition of glycine to a final concentration of $0.125 \mathrm{M}$. After washing $2 \mathrm{X}$ with ice-cold PBS containing $1 \mathrm{X}$ protease inhibitor cocktail (PIC) (Sigma) cells were resuspended in $25 \mathrm{mls}$ ice-cold cell lysis buffer 1 (10mM Tris-CL pH 8.0, 10mM EDTA, $10 \mathrm{mM}$ Na-Butyrate, $0.5 \mathrm{mM}$ EGTA, $0.25 \%$ Triton X-100, 1X PIC, $1 \mathrm{mM}$ PMSF) and incubated on ice $10 \mathrm{~min}$. Nuclei were recovered by centrifugation and resuspended in lysis buffer $2(0.2 \mathrm{M} \mathrm{NaCl}, 10 \mathrm{mM}$ Tris-CL pH 8.0, 1mM EDTA, 0.5mM EGTA, 1X PIC, 1 mM PMSF) and incubated $10 \mathrm{~min}$. Samples were centrifuged and resuspended in $2 \mathrm{ml}$ sonication buffer ( $10 \mathrm{mM}$ Tris-Cl, pH 8.0, $1 \mathrm{mM}$ EDTA, $0.5 \mathrm{mM}$ EGTA). Chromatin was sonicated 12 rounds for $20 \mathrm{~s}$ using a 250 Branson Sonifier (30\% output) alternating with $30 \mathrm{~s}$ incubations on ETOH/ice. Chromatin was centrifuged $10 \mathrm{~min}$ at 14,000 RPM to pellet debris, and stored at $-80^{\circ} \mathrm{C}$. Chromatin samples were pre-cleared for $1-2 \mathrm{~h}$ at $4^{\circ} \mathrm{C}$ by adding $50 \mu \mathrm{l}$ Protein A/ssDNA-agarose beads (Upstate Biotechnology), followed by incubation with antibody in a 10 -fold dilution of 1 X RIPA buffer (140mM NaCl, $1 \%$ Triton $\mathrm{X}-100,0.1 \%$ deoxycholate, and $1 \mathrm{mM}$ PMSF) at $4^{\circ} \mathrm{C}$ overnight. Immune complexes were recovered at $4^{\circ} \mathrm{C}$ for $1 \mathrm{~h}$ using $60 \mu \mathrm{l}$ Protein A/ss DNA agarose beads. Complexes were washed five times with IP1 (0.1\% SDS, 1\% Triton X-100, 2 mM EDTA, 20 mM Tris, $\mathrm{pH}$ 8.0, 150 $\mathrm{mM} \mathrm{NaCl})$, once with IP2 $(0.1 \%$ SDS, $1 \%$ Triton X-100, 2 mM EDTA, $20 \mathrm{mM}$ Tris, $\mathrm{pH} 8.0,500 \mathrm{mM} \mathrm{NaCl}$ ), and twice with Tris-EDTA $\mathrm{pH}$ 8.0. Immunoprecipitation reactions and input chromatin were digested with $200 \mu \mathrm{g} / \mathrm{ml}$ RNase A for $1 \mathrm{~h}$ and $200 \mu \mathrm{g} / \mathrm{ml}$ proteinase $\mathrm{K}$ in TE with
$0.5 \%$ SDS for $2 \mathrm{~h}$ at $55^{\circ} \mathrm{C}$. Crosslinks were reversed overnight at $65^{\circ} \mathrm{C}$. Samples were extracted once with phenol/chloroform and once with chloroform/isoamyl alcohol, ETOH precipitated and resuspended in $12 \mu \mathrm{l}$ TE.

\section{Sequence-specific PCR with ChIP products}

Due to the high sequence conservation of the four $I \gamma$ subclass promoters it was difficult to selectively amplify only the $\mathrm{I} \gamma 1$ promoter region using standard PCR techniques. Therefore, in order to distinguish $\mathrm{I} \gamma 1$ from the remaining subclasses, PCR was carried out with primers that contained a minimum number of 4 naturally occurring base alterations and 3-4 additional changes that were intentionally introduced into the primer sequence. This level of mispriming still allowed amplification of the $\mathrm{I} \gamma 1$ promoter sequence. To test the specificity of primers, PCR was performed using either $0.2 \mathrm{ng}$ purified HindIII-BamHI I $\gamma$ subclass promoter sequence, $1 \mu \mathrm{l}$ of 1:200 dilution of input chromatin, $3 \mu \mathrm{l}$ of undiluted or 10-fold serial diluted immunoprecipitant in a $50 \mu \mathrm{l}$ reaction containing $10 \mathrm{mM}$ Tris $\mathrm{Cl}(\mathrm{pH} 8.1), 1.5$ $\mathrm{mM} \mathrm{MgCl} 2,50 \mathrm{mM} \mathrm{KCl}, 0.1 \%$ Triton X-100, 5\% DMSO, $0.2 \mathrm{mM}$ dNTPs, $2.5 \mathrm{U}$ Taq (Promega) and $100 \mathrm{ng}$ of $5^{\prime}$ and 3' primers: I $\gamma$ non-specific- $5^{\prime}$ gec ctc tga ccc aga aac c $3^{\prime}$; $5^{\prime}$ cct tcc tgt tct ggc gag gt $3^{\prime}$; I $\gamma 1$ specific- $5^{\prime}$ tcc atg tag tgc cgg aca cga ccc cat $3^{\prime} ; \mathrm{I} \gamma 1$ WT $5^{\prime}$ tcc atg tgg ggc cgg cct cga ccc cat $3^{\prime} ; \mathrm{I} \gamma 1 \Delta 1 \mathrm{bp} 5^{\prime}$ tcc atg tgg tgc cgg cct cga ccc cat $3^{\prime} ;$ I $\gamma 1 \Delta 2 b p 5^{\prime}$ tcc atg tgg tgc cgg cca cga ccc cat $3^{\prime}$; I $\gamma 1 \Delta 3 \mathrm{bp} 5^{\prime}$ tcc atg tgg tgc cgg aca cga ccc cat 3; IgHG'$5^{\prime}$ ctc cac caa ggg ccc atc ggt $3^{\prime} ; 5^{\prime}$ caa atc ttg tga caa aac tca cac at $3^{\prime}$. Amplification of all reactions was for 35 cycles, with a hot-start at $3 \mathrm{~min}$ at $92^{\circ} \mathrm{C}, 30 \mathrm{~s}$ at $92^{\circ} \mathrm{C}, 45 \mathrm{~s}$ at $56^{\circ} \mathrm{C}, 45 \mathrm{~s}$ at $72^{\circ} \mathrm{C}$, and $3 \mathrm{~min}$ at $72^{\circ} \mathrm{C}$. Final PCR amplifications were subjected to gel electrophoresis and bands were quantified using Kodak imaging software.

\section{RESULTS AND DISCUSSION}

\section{Isolation and characterization of $\mathrm{CD}_{19}{ }^{+}$human B cells from blood}

Successful ChIP is highly dependent on having sufficient starting material to carry out a number of immunoprecipitation reactions using chromatin from the same source of cells. Therefore, using primary human B cells in this assay is highly challenging given the

Dryer \& Covey - Use of chromatin immunoprecipitation (ChIP) to detect transcription factor binding to highly homologous promoters in chromatin isolated from unstimulated and activated primary human B cells 
relatively low numbers of isolated B cells from peripheral blood. Also, since our goal was to analyze factor binding before and after activation through CD40, it was critical that the isolated $\mathrm{B}$ cells were non-activated prior to isolation. We therefore set out to isolate CD19+ IgG- B cells to obtain a population of B cells that were predominantly $\mathrm{IgM}^{+} / \mathrm{IgD}^{+}$. From $500 \mathrm{ml} /$ unit of human blood, we were able to isolate an average of $3.4 \times 10^{7} \mathrm{~B}$ cells/unit or $4.9 \%$ of the total peripheral blood mononuclear cells (PBMCs) (Table 1).

\begin{tabular}{llll}
\hline \multicolumn{4}{c}{ Table 1: Leukocyte and B cell yields from human blood. } \\
\hline Cell & $\begin{array}{l}\text { Range of cells obtained } \\
\text { (total units =10) }\end{array}$ & $\begin{array}{l}\text { Avg. cell } \\
\text { number }\end{array}$ & $\begin{array}{l}\text { yield } \\
\text { population }\end{array}$ \\
\hline PBMCs & $2.5 \times 10^{8}-1.5 \times 10^{9}$ & $7.0 \times 10^{8}$ & $100 \%$ \\
CD19+ & $1.5 \times 10^{7}-9.5 \times 10^{7}$ & $4.0 \times 10^{7}$ & $5.7 \%$ \\
CD19+/IgG- & ND & $3.4 \times 10^{7}$ & $4.9 \%$ \\
\hline
\end{tabular}

The positively selected population was shown to be approximately $98 \% \mathrm{CD}^{2} 0^{+}$(pan B cell marker). We selected to use anti-CD20 antibody to measure successful $B$ cell isolation, since use of the $\mathrm{CD} 19^{+}$magnetic beads may cause $\mathrm{CD} 19^{+}$epitopes to be obscured. Further purification of this population by negatively selecting $\mathrm{IgG}^{+} \mathrm{B}$ cells produced cells that were $87 \% \mathrm{IgM}^{+}$and $89 \%$ $\operatorname{IgD}^{+}$(Fig. 1).

\section{Anti-CD19 Selected Population}

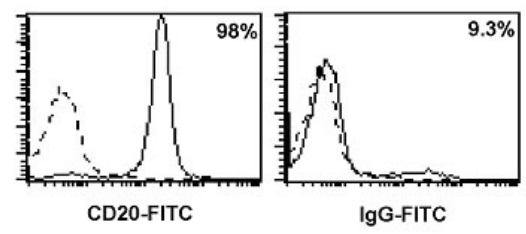

Anti-CD19 population negatively selected with anti-lgG mAb

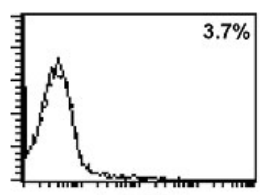

IgG-FITC

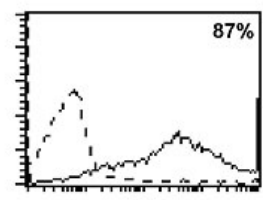

IgM-PE

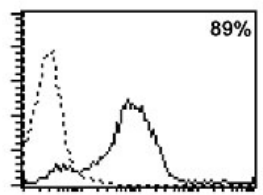

IgD-FITC
Fig. 1: Purification of a IgM+//gD+ population of primary B cells. CD19+ isolated IgM $^{+} /$IgG $^{-}$peripheral $B$ cells were analyzed for surface expression of CD20 and IgG (upper panel). IgG, IgM, and IgD expression was determined following subsequent negative selection using anti-lgG antibody (lower panel). Percentages of positively stained cells are indicated in the right corner of each histogram. The stippled line represents the isotype control for each antibody.
The percentage of $\mathrm{IgG}^{+} \mathrm{B}$ cells left in the final population was below that observed with the isotype control and supported out assertion that the starting population was predominantly $\operatorname{IgM}^{+} / \operatorname{IgD}^{+} \mathrm{B}$ cells (Table 2 ).

\begin{tabular}{lc}
\hline \multicolumn{2}{l}{ Table 2: Phenotypic analysis of B cell populations. } \\
\hline Surface marker & Average expression \\
\hline CD20 & $98 \%$ \\
IgG- pre selection & $9.3 \%$ \\
IgG- post selection & $3.7 \%$ \\
Isotype control & $5.3 \%$ \\
\hline
\end{tabular}

To obtain sufficient numbers of $\mathrm{CD}^{+} 9^{+} / \mathrm{IgM}^{+} \mathrm{B}$ cells for each ChIP assay, units were pooled prior to stimulation. Purified CD19+/IgG- B cells were stimulated with soluble, trimerized CD154 for $2 \mathrm{hr}$. Because of our interest in analyzing the interaction of Rel/NF- $\mathrm{kB}$ subunits with chromatin, it was necessary to confirm that the

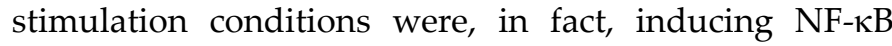
activity. To this end, EMSAs were carried out with nuclear extracts from resting and activated $B$ cells with and without antibody to the p50 NF- $\mathrm{kB}$ subunit. As seen in Figure 2, prior to activation there is a measurable level of NF- $\mathrm{KB}$ activity in the B cells (lane 1). However, upon activation there is a significant increase of binding activity (lane 2) and a considerable amount of the binding activity is super-shifted with anti-p50 antibodies (lane 3). This result indicated that under the stated conditions of CD40 activation, there was a marked increase in NF- $\mathrm{KB}$ activity in the primary $\mathrm{CD}^{+} 9^{+} / \mathrm{IgG}^{-} \mathrm{B}$ cells.

In addition to the intrinsic challenges of the ChIP protocol (reviewed in $(24,25)$ ) our experiments had the added difficulty of establishing binding specificity to a single promoter within a class of four highly homologous gene promoters. As shown in Figure 3, these promoters all contain multiple NF- $\mathrm{kB}$ sites; four of them (sites 3-6) have been shown to be active in regulating transcription in transfection studies in both 
mouse and human B cells $(15,26,27)$. It was critical for the questions that we were asking, i.e. whether binding at the I $\gamma 1$ locus occurred prior to, or after activation, to be able to attribute in vivo NF-kB/rel, CREB, and p300 binding to the $\mathrm{I} \gamma 1$ and not the $\mathrm{I} \gamma 2-4$ promoters. Therefore, once the DNA was isolated from chromatin we carried out PCR with primers designed to distinguish between $I \gamma 1$ and $I \gamma 4$ based on size and between $I \gamma 1$ and I $\gamma 3$ based on differential amplification. This protocol was adapted from the mutagenically separated PCR (MSPCR) technique in which variable length allele-specific primers are used to identify single allelic point mutations $(14,28,29)$. In addition to size differences in the $\mathrm{I} \gamma 1$ and I $\gamma 4$ 3' primers, an additional base change was introduced to reduce potential cross-reactions between near identical sequences thereby increasing the specificity of the reaction. We generated a $5^{\prime}$ primer that recognized only the I $\gamma 1, \mathrm{I} \gamma 3$, and $\mathrm{I} \gamma 4$ promoter sequences (I-1/4) sequences and two variable length $3^{\prime}$ primers (I-1 and I4) that amplified different sized $I \gamma$ sequences corresponding to $\mathrm{I} \gamma 1$ or $\mathrm{I} \gamma 4$ (Fig. 3B). This approach proved to be unfeasible for quantitation-based experiments since the efficiency of amplification of the two reactions was found to be markedly different (arrows, Fig. 3B). Additional primer pairs were tested and they too presented quantification problems due to the preferential amplification of individual products (data not shown).

To address the issues presented with MS-PCR, additional primer sets were generated, for which each I $\gamma$ subclass was amplified in a separate reaction using the same $5^{\prime}$ primer (ChIP 5'), but distinct 3' primers that hybridized to a region of each promoter that had a minimum of three base pair differences among the sequences (ChIP 3' I $\gamma 1$ and ChIP 3' I $\gamma 4$ ) (Fig. 4A). Again, additional nontemplated base changes were added within the primer sequences to limit cross-reactivity and amplification of multiple subclasses (28). As shown in Figure 4B, The number of induced changes was determined by testing various 3' primers, denoted $\mathrm{I} \gamma 1 \Delta 3, \Delta 2$, and $\Delta 1 \mathrm{bp}$, in PCR reactions containing each $\mathrm{I} \gamma$ subclass promoter region as a cloned DNA template. In order to eliminate amplification of all other subclasses, a $3^{\prime}$ primer, containing at least 2 additional bp changes, was required (upper panel). However, to eliminate potential primerdimer products and reduce the GC-stretches, another 3' primer was generated that contained 4 induced alterations. Using this $\mathrm{I} \gamma 1$ promoter-specific primer the promoter sequences of the other three $\mathrm{I} \gamma$ subclasses failed to amplify (Fig. 4C). The size of the fragment generated with this set of $\mathrm{I} \gamma 1$-specific primers $(\sim 380 \mathrm{bp})$ precluded us from using these primers effectively in qPCR. Thus, we had to expand our PCR analysis by carrying out dilution PCR to determine the amount of enrichment with specific antibodies under distinct conditions of stimulation.

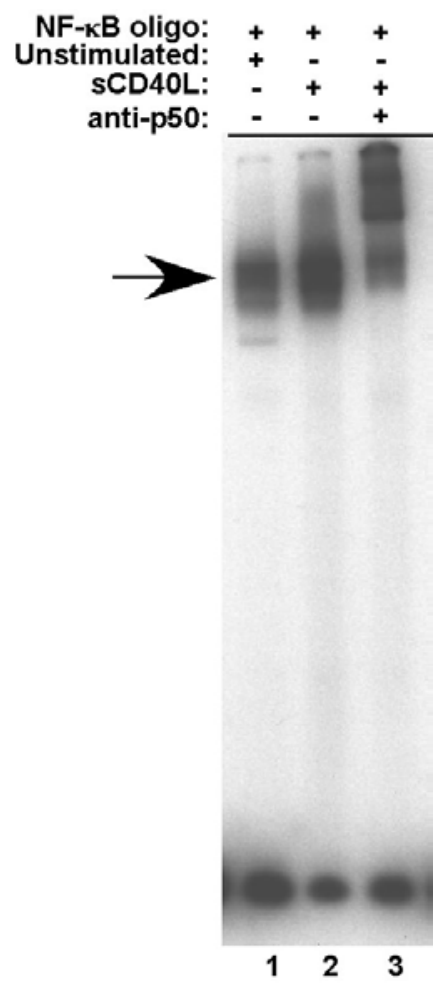

Fig. 2: NF- $\kappa B$ activity is upregulated in response to $C D 40$ signaling. NF- $\kappa B$ consensus oligonucleotide was incubated with extracts from $\operatorname{lgM}^{+} / \lg$ peripheral B cells either unstimulated (lane 1) or stimulated for $2 \mathrm{~h}$ with $0.5 \mathrm{\mu g} / \mathrm{ml} \mathrm{sCD} 40 \mathrm{~L}$ (lanes 2 and 3). Supershifting was performed by subsequent incubation with a p50 antibody (lane 3). NF-kB complex is indicated by the arrow. 
A.

NFFB1

-310 $\gamma 1$... AAGCTTCAGA TGAGAGGCCC AGGTATTGAG AGGCTGAGAT CACGGGCAGA ATGGTCATAA TCOCTCCCAG TATCAGTCCA భ2... AAGCTTCAGG TGAGAGGCCC AGGTATTGA AGGCTGAGAT CACGGGCAGA ATGGTCATAA TCACTOCCAO TATCAOTCCA ү3... AMGCTTCAGA TGAGAGGCCC AgGTATTGA AgGCTGAgAT CACGGGCAGA ATGGTCATAA TCGTTCCCAG TCTCAGTCCA

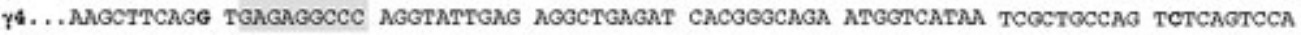

NF-KB2

ү1... ФCCCCAGGOA CTCAGAGACA GAOAAAAGAO CAGCACACAA GGTCIGGGCT CCCCACCTTC TCCCGTGAGT ACGGGGGAGT

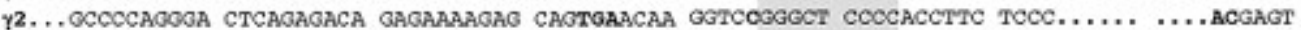
$\gamma 3$... $\triangle C C C C A G O G A$ CTCAGAGACA GAOAAAROAG CAGCACACAR GGTCOGGGCT CCOCACCTTC TCCCGTGAGI ATGGGGGAGT భ4... $Ф C C C C A G G G A$ CTCAGAGACA GAGAAAGAG CAGCACACAA GGTCOGGGCT COCCACCTTC TCCCGTGAGT ATGGGGGAGT NF $=$. B 3

ү1...ATGGGGGCAG CCACCRCCCC CATCCCCACA CACCCATGAG GCAGCCTCGG CTGTGTENG ACTCCOCCTC GCCCTCTGAC ү2...ARGGGGGCAG CCACCACCCC CATCCCCACA CACCCATGAG GCAGCCTCGG CTGTGICTGG ACTCCOCCTT ACCCTGTGAC ү3...ARGGGGGCAG CCACCACCCC AATCCCCACA CACCCATGAG GCAGCCTCAG CTGTGTCRG ACTCCOCCTC GCCCTCTGAC Y4... AGGGGGGCAG CCACCACCCC MATCCCCACA CACCCATGAG GCAGCCTCGG CTCTOTORGG ACTCCCCCTC GCCCTCTGAC $\mathrm{NF}-\mathrm{kB} 4$ NF-xB5

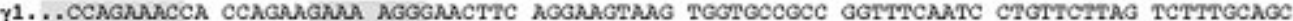
$\gamma 2$... CCAGAAACCA CCAGARGAAA AGGGAACTTC AGGAAGTAAG CGGTGCCGCC GGTTTCAATC CTGTTCTTAG TCTTTECAGC Y3...ACAGAAACCA CCAGAAGAAA AGGGAACTTC AGGAAGTAAG TGGTGCCGCC GGTTTCAATC CTGTTCTTAG TOTTTGCAGC Y4...ACAGAAACCA CCAGAAGAAA AGGGACTTC AGGAAGTAAG GGGTGCCGCC GGTTTCAATC CTGTTCTTAG TCTTTCCAGC

ү1... GTGGAGTCA CACACCTGGO GACCTGGOGG COGAGCTOTO ATTTCCTAGG AAGACAAATA TCGGCTGACG GCAGGGGGG భ2...GTGGAGTTCA CACCCCTGG GACCTEACGG COGAGCTTGG ATTTCCTAGG AAGACAAATA GCGGCTGACG GCGTGGGCGA ү3...GTGGAGTTCA CAACCCTGGG GACCTGGGG COGAGCTGTG ATTTCCTAGG AAGACAAATG GCAGCTGACA GCGTGGGCAA భ4...GTGGAGTTCA CACOCCTGGG GACCTGGGAC CTGAGCTGTG ATTTCCTAGG AAGACAAATA GCGGCTGACG GCGGGGGCGG NF-kB6

ү1... GGCTGCCCAC ATGTACCTCG CCAGAACAGG AAGGGCTGAG ACCOCCACCT CGGTGAGTGG GGTCAGCACA GGGCAGGGGC

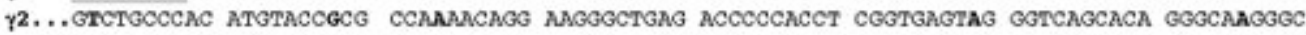

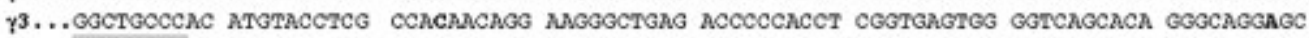

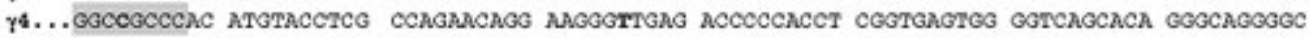

ү1...ACAGGCTCGG GAGGAGG..G TCAGCCTGGG GCGAGCGTGG GCGCTCCTGG ACCTGAGATG CTGARCAGGC TCCAAGAGGC 2...ACAGGCTCGG GAGGAGAAGG ACAGCCTGG TCGAGCGT.G GCOCTOCTGG ACCTCAOCIG CTGAACAGGC TACAAGAGGC భ3...ACAOOCTC. . AGGAGAAGO ACAOCCTOOO CGCAOCATCO QCOCTOCTOO ACCTGAOCTG CTGAACAOGC TGCAAOAGGC

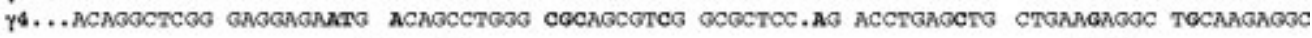

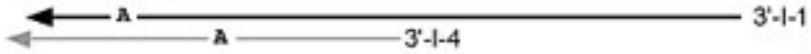

1...TGGGGAGACA TGGGGNCGAG GCCGGCCCCAC ATGGAGGCCC AAGCGGAGCC AGCACGGOG GAGGTCG +315 Ү2...7GGGGAGACG TGGGGGCARG GCCAGCCCCAC ATGGAAGCCC RAGCGGAGCC AGCACGGGG GAGGTGG Ү... TGGGGAGAGG CTGGGGCGAG GCCAGCCCCAC ATGGACACCT AAGCGGAGCC AGCACGGGG GAGGTGG Y... TGGGGaGaCG CGGGCGCGAG GCCAGCACCAC ATGGAAGCCC ARGCGGAGCC AGCACGGGG GaGGTGG

B.

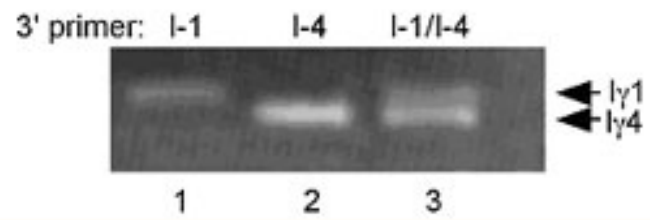

Fig. 3: Nucleotide sequence of the four human ly proximal promoter regions. (A) Alignment of the four ly subclass full length proximal promoters is shown, with nucleotide variances indicated in bold. NF-KB binding sites are denoted by shading. Initial primer sequences used for ChIP PCR amplification are indicated by arrows. Numbering is relative to the ly1 transcriptional start site defined by Sideras et al. (30). (B) Total chromatin from CD19+ B cells was amplified using the 5'-I-1/4 primer and either the 3'-1-1 primer (lane 1), the 3'l-4 primer (lane 2) or both the 3' I-1 and the 3'I-4 primers. Products representing the ly1 and ly4 promoters were separated on a 1.5\% TBE gel.

Dryer \& Covey - Use of chromatin immunoprecipitation (ChIP) to detect transcription factor binding to highly homologous promoters in chromatin isolated from unstimulated and activated primary human B cells www.biologicalprocedures.com 
A.

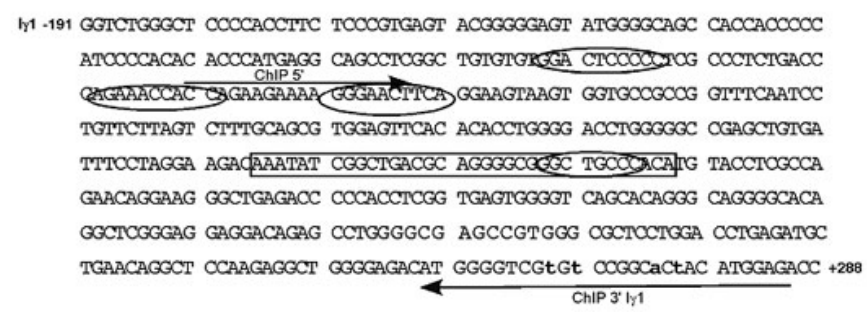

B.

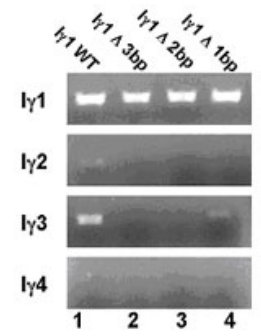

c.

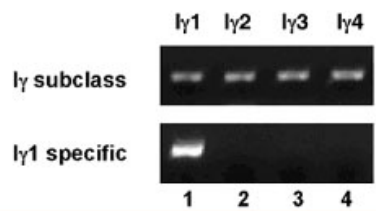

Fig. 4: The Iy1 proximal promoter is selectively amplified with PCR. (A) Shown is a schematic of the IY1 proximal promoter sequence from -191 to +288 (see Fig. 2), with arrows indicating the forward and reverse primers used to amplify ChIP products. Non-templated nucleotide substitutions, introduced into the 3' primer sequence, are denoted in lower case. NF- $\mathrm{KB}$ sites 3 through 6 are indicated by ovals, whereas the 36 bp sequence is enclosed by a rectangle. (B) PCR amplification of cloned DNA containing the specific ly promoter sequences was performed using ly1-specific primers with exchange of 0 (lane 1), 3 (lane 2), 2 (lane 3 ) and 1 (lane 4) non-templated nucleotides in the ly1 sequence. (C) PCR amplification of cloned DNA sequences of IY1, IY2, IY3 and IY4 promoter sequences using the ChIP IY1-5' and IY1-3' primers (Fig. 3C used with permission, The Journal of Immunology 2005; 175:4499-4507).

The objective of our experiments, using the selective primers, was to analyze NF- $\mathrm{kB}, \mathrm{CREB}$ and p300 binding specifically to the $\mathrm{I} \gamma 1$ promoter in resting and CD40activated primary human B cells. Because the strength of the $\mathrm{I} \gamma 1$ promoter appears to be higher than the other $\mathrm{I} \gamma$ subclass promoters in both primary B cells and a number of $\mathrm{B}$ cell lines, and the fact that we observed transcription factor binding in vitro, led us to question whether there was selective binding to the I $\gamma 1$ promoter in vivo. Using the ChIP assay with chromatin purified from resting and CD40-stimulated CD19+IgG- B cells we were able to see a distinct difference in binding of CREB and p300 in unstimulated versus stimulated B cells (Fig. 5).

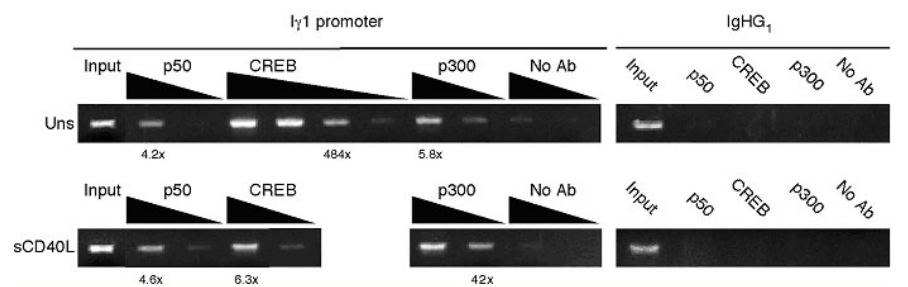

Fig. 5: Co-activator binding is enhanced in CD40-activated B cells.

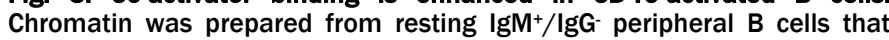
was either unstimulated (upper panel) or stimulated for $2 \mathrm{~h}$ with $0.5 \mu \mathrm{g} / \mathrm{ml}$ sCD40L. Immunoprecipitation was carried out with antibodies specific for p50, CREB and p300. Eluted DNA was amplified with Iy1-specific primers (left panels) or control IgHG 1 primers (left panels). 10-fold serial dilutions of the chromatin (starting with a 1:10 dilution of the immunoprecipitated product) were used to demonstrate linearity of the PCR reaction. Products were quantified by determining the fold increase signal over the "no antibody" signal (used with permission, The Journal of Immunology 2005; 175:4499-4507).

Specifically, we observed that CREB binding was more pronounced in unstimulated $B$ cells compared to stimulated B cells suggesting that CREB binds on this promoter prior to and after CD40 activation. With CD40 signaling there is a distinct loss of CREB signal but an enhancement of co-activator p300 binding indicating a recruitment of this factor to the $\mathrm{I} \gamma 1$ promoter (compare upper and lower panels). As noted above, quantitation of the bands were carried out using dilution PCR to assess the enrichment of the $\mathrm{I} \gamma 1$ band in the different samples.

In conclusion, using a modified ChIP protocol with primary human B cells we were able to show selective binding of transcription factors and co-activators at the I $\gamma 1$ promoter. Importantly, with this assay we also demonstrated an in vivo change in factor binding upon stimulation of naïve B cells upon activation through the CD40 signal transduction pathway.

\section{ACKNOWLEDGMENTS}

We thank Dr. Nancy Rice (National Cancer institute, Bethesda, MD) for the NF-кB antibodies. Also, Dr. Celíne Gelínas (University of Medicine and Dentistry of New Jersey, Piscataway, NJ), Ralph Bernstein (CBER, FDA, Bethesday, MD) and Caroline Woo (Albert Einstein college of Medicine, Bronx, NY) are gratefully acknowledged for their input regarding technical issues related to ChIP. Finally, the help and insightful comments of Frank Sinquett and other members of the Covey lab were greatly appreciated during the entire course of this study. This work was supported by a National Institutes of Health Grant RO1AI3708 (to L. R. C.) and a National Institutes of Health Training Fellowship T32AI07403 (to R. L. D.). The authors have no conflicts of interest to declare related to this publication. 


\section{REFERENCES}

1. Kuo $\mathrm{MH}$, Allis $\mathrm{CD}$. In vivo cross-linking and immunoprecipitation for studying dynamic Protein:DNA associations in a chromatin environment. Methods 1999; 19:425-433.

2. Wells J, Farnham PJ. Characterizing transcription factor binding sites using formaldehyde crosslinking and immunoprecipitation. Methods 2002; 26:48-56.

3. Stavnezer J. Molecular processes that regulate class switching. Curr Top Microbiol Immunol 2000; 245:127168.

4. Stavnezer J, Amemiya CT. Evolution of isotype switching. Semin Immunol 2004; 16:257-275.

5. Gaff C, Gerondakis S. RNA splicing generates alternate forms of germline immunoglobulin alpha heavy chain transcripts. Int Immunol 1990; 2:11431148.

6. Gerondakis S. Structure and expression of murine germ-line immunoglobulin epsilon heavy chain transcripts induced by interleukin 4. Proc Natl Acad Sci USA 1990; 87:1581-1585.

7. Lebman DA, Nomura DY, Coffman RL, Lee FD. Molecular characterization of germ-line immunoglobulin A transcripts produced during transforming growth factor type beta-induced isotype switching. Proc Natl Acad Sci USA 1990; 87:3962-3966.

8. Lutzker S, Rothman P, Pollock R, Coffman R, Alt FW. Mitogen and IL-4 regulated expression of germline Ig $\gamma 2 \mathrm{~b}$ transcripts: evidence for directed heavy chain class switching. Cell 1988; 53:177-184.

9. Radcliffe G, Lin YC, Julius M, Marcu KB, Stavnezer J. Structure of germ line immunoglobulin alpha heavychain RNA and its location on polysomes. Mol Cell Biol 1990; 10:382-386.

10. Rothman P, Chen YY, Lutzker S, Li SC, Stewart V, Coffman R, Alt FW. Structure and expression of germline immunoglobuin heavy-chain epsilon transcripts: interleukin-4 plus lipopolysaccharidedirected switching to C epsilon. Mol Cell Biol 1990; 10:1672-1679.

11. Rothman P, Lutzker S, Gorham B, Stewart V, Coffman R, Alt FW. Structure and expression of germline immunoglobulin $\gamma 3$ heavy chain gene transcripts: implications for mitogen and lymphokine directed class switching. Int Immunol 1990; 2:621-627.

12. Ford GS, Yin CH, Barnhart B, Sztam K, Covey LR. CD40 ligand exerts differential effects on the expression of $\mathrm{I} \gamma$ transcripts in subclones of an IgM+ human B cell lymphoma line. J Immunol 1998; 160:595-605.

13. Bhushan A, Covey LR. CREB/ATF proteins enhance the basal and CD154- and IL-4-induced transcriptional activity of the human Igamma1 proximal promoter. Eur J Immunol 2001; 31:653-664.

14. Dryer RL, Covey LR. A Novel NF-\{kappa\}BRegulated Site within the Human I\{gamma\}1 Promoter Requires p300 for Optimal Transcriptional Activity. J Immunol 2005; 175:4499-4507.

15. Lin S-C, Stavnezer J. Activation of NF- $\mathrm{kB} /$ Rel by $\mathrm{CD} 40$ engagement induces the mouse germ line immunoglobulin C $\gamma 1$ promoter. Mol Cell Biol 1996; 16:4591-4603.

16. Lin S-C, Wortis HH, Stavnezer J. The ability of CD40L, but not lipopolysaccharide, to initiate immunoglobulin switching to immunoglobulin G1 is

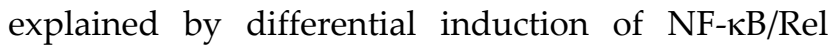
Proteins. Mol Cell Biol 1998; 18:5523-5532.

17. Snapper CM, Rosas FR, Zelazowski P, Moorman MA, Kehry MR, Bravo R, Weih F. B cells lacking relB are decfective in proliferative responses, but undergo normal B cell maturation to Ig secretion and Ig class switching. J Exp Med 1996; 184:1537-1541.

18. Jumper MD, Nishioka U, Davis LS, Lipsky PE, Meek K. Regulation of human $B$ cell function by recombinant CD40 ligand and other TNF-related ligands. J Immunol 1995; 155:2369-2378.

19. Jumper MD, Splawski JB, Lipsky PE, Meek K. Ligation of CD40 induces sterile transcripts of multiple $\mathrm{Ig} \mathrm{H}$ chain isotypes in human B cells. J Immunol 1994; 152:438-445.

20. Fujieda S, Zhang K, Saxon A. IL-4 plus CD40 monoclonal antibody induces human B cells $\gamma$ subclass-specific isotype switch: Switching to $\gamma 1, \gamma 3$, and $\gamma 4$, but not $\gamma 2$. J Immunol 1995; 155:2318-2328.

21. Dignam J, Lebovitz RM, Roeder RD. Accurate transcription initiation by RNA polymerase II in a soluble extract from isolated mammalian nuclei. $\mathrm{Nucl}$ Acids Res 1983; 11:1475-1489.

22. Orlando V, Strutt H, Paro R. Analysis of chromatin structure by in vivo formaldehyde cross-linking. Methods 1997; 11:205-214. 
23. Parekh BS, Maniatis T. Virus infection leads to localized hyperacetylation of histones $\mathrm{H} 3$ and $\mathrm{H} 4$ at the IFN-beta promoter. Mol Cell 1999; 3:125-129.

24. Orlando V. Mapping chromosomal proteins in vivo by formaldehyde-crosslinked-chromatin immunoprecipitation. Trends Biochem Sci 2000; 25:99104.

25. Weinmann AS. Novel ChIP-based strategies to uncover transcription factor target genes in the immune system. Nat Rev Immunol 2004; 4:381-386.

26. Schaffer A, Cerutti A, Shah S, Zan H, Casali P. The evolutionarily conserved sequence upstream of the human Ig heavy chain $S$ gamma 3 region is an inducible promoter: synergistic activation by CD40 ligand and IL-4 via cooperative NF-kappa B and STAT-6 binding sites. J Immunol 1999; 162:5327-5336.

27. Warren WD, Roberts KL, Linehan LA, Berton MT. Regulation of the germline immunoglobulin Cgamma1 promoter by CD40 ligand and IL-4: dual role for tandem NF-kappaB binding sites. Mol Immunol 1999; 36:31-44.

28. Rust S, Funke H, Assmann G. Mutagenically separated PCR (MS-PCR): a highly specific one step procedure for easy mutation detection. Nucl Acids Res 1993; 21:3623-3629.

29. Schluter B, Erren M, Schotte H, Junker R, Rust S, Assmann, G. The mutagenically separated polymerase chain reaction is a rapid and reliable method for genotyping of the tumour necrosis factoralpha promoter polymorphism (-308 G/A). Clin Chim Acta 2002; 320:135-138.

30. Sideras P, Mizuta TR, Kanamori H, Suzuki N, Okamoto M, Kuze K, Ohno H, Doi S, Fukuhara S, Hassan MS, et al. Production of sterile transcripts of $C$ gamma genes in an IgM-producing human neoplastic B cell line that switches to IgG-producing cells. Int Immunol 1989; 1:631-642. 


\section{PROTOCOLS}

1. Transfer $5 \times 10^{7}$ cells and dilute to $100 \mathrm{ml}$ volume with $37^{\circ} \mathrm{C}$ pre-warmed media, add $10 \mathrm{ml}$ of $11 \%$ formaldehyde solution while swirling.

2. Incubate at $37^{\circ} \mathrm{C} 7-10 \mathrm{~min}$, stop crosslinking by adding glycine to a final concentration of $0.125 \mathrm{M}$, incubate for 5 minutes on ice.

3. Harvest cells at 1250 RPM for 5 minutes and wash twice with cold 1X PBS.

4. Pellet cells and resuspend in $25 \mathrm{ml}$ of Lysis solution 1, incubate on ice 10 minutes, with periodic mixing.

5. Pellet cells at 2500 RPM and resuspend pellet in $25 \mathrm{ml}$ lysis solution 2, to ensure complete resuspension, add $1 \mathrm{ml}$ to pellet first and pipet up and down, add remaining $24 \mathrm{ml}$ and place at $4^{\circ} \mathrm{C}$ on rocker.

6. Pellet and discard supernatant, resuspend pellet in $2 \mathrm{mls}$ sonication buffer.

7. Add $200 \mathrm{mg}$ of acid washed glass beads for sonication.

8. Place tube in ethanol/ice beaker to keep cold during sonication, position tube so that probe is near the bottom, but not touching. This will minimize frothing of samples.

9. Sonicate for $8-12$ rounds, for 20 secs at $30 \%$ output, ice for 1 minute between each interval. Change ice frequently to ensure proper cooling of samples.

10. Spin chromatin at $14 \mathrm{~K}$ RPM for 10 minutes to pellet debris.

11. Aliquot samples $200 \mu \mathrm{l}$ and and continue with assay, or store at $-80^{\circ} \mathrm{C}$. Set aside $20 \mu \mathrm{l}$ to use as input.

12. Thaw samples and dilute 1:10 with 1 X RIPA buffer, add $50 \mu$ of Protein A/ssDNA and pre-clear chromatin for 1 hour on a rotator at $4^{\circ} \mathrm{C}$.

13. Spin at $1200 \mathrm{RPM}$ to remove beads and transfer supernatant to a fresh tube.

14. Add $2-4 \mu \mathrm{g}$ of the desired antibody, rotate overnight at $4^{\circ} \mathrm{C}$.

15. Add $60 \mu \mathrm{l}$ Protein A/ssDNA slurry to each sample and rotate $1 \mathrm{hr}$.

16. Spin at $1200 \mathrm{RPM}$ for 3 minutes to pellet beads.

17. Wash 5 times with IP1, with 5 minute rotation at RT.

18. Wash once with IP2, with a 5 minute rotation, and twice with TE.

19. To reverse crosslinke, bring bead pellet up to 400 with TE and add $8 \mu$ RNAse A $(10 \mathrm{mg} / \mathrm{ml})$ to final of $200 \mu \mathrm{g} / \mathrm{ml}$, incubate 1 hour at $55^{\circ} \mathrm{C}$. ${ }^{*}$ Remove TC input samples from $-80^{\circ} \mathrm{C}$ and reverse $\mathrm{X}$-links at this time.

20. Add $20 \mu \mathrm{l}$ of $10 \%$ SDS (FC $0.5 \%$ ) and $8 \mu \mathrm{l}$ Proteinase $\mathrm{K}(10 \mathrm{mg} / \mathrm{ml})$ and incubate $2-3$ hours at $55^{\circ} \mathrm{C}$, move to $65^{\circ} \mathrm{C}$ overnight.

21. Phenol chloroform samples once, chloroform/isoamyl once, and ethanol precipitate sample.

22. Resuspend final IP product in $12 \mathrm{TE}$, use $3 \mu \mathrm{l}$ per $50 \mu \mathrm{l}$ PCR reaction.

\section{Chromatin immunoprecipitation assay}

\begin{tabular}{|c|c|c|c|}
\hline Formaldehyde solution & Lysis solution 1 & Lysis solution 2 & Sonication buffer \\
\hline $11 \%$ formaldehyde & Tris-CL & $0.2 \mathrm{M} \mathrm{NaCl}$ & $10 \mathrm{mM}$ Tris $\mathrm{Cl}, \mathrm{pH} 8.0$ \\
\hline $0.1 \mathrm{M} \mathrm{NaCl}$ & 10mM EDTA & $10 \mathrm{mM}$ Tris- $\mathrm{Cl}, \mathrm{pH} 8.0$ & $1 \mathrm{mM}$ EDTA \\
\hline 1mM EDTA & $10 \mathrm{mM}$ Na-Butyrate, $0.5 \mathrm{mM}$ & $1 \mathrm{mM}$ EDTA & $0.5 \mathrm{mM}$ EGTA \\
\hline $0.5 \mathrm{mM}$ EGTA & EGTA & $0.5 \mathrm{mM}$ EGTA & \\
\hline 50mM HEPES, pH 8.0 & $0.25 \%$ Triton $X-100$ & 1X PIC & \\
\hline & 1X PIC & $1 \mathrm{mM}$ PMSF & \\
\hline & $1 \mathrm{mM}$ PMSF & & \\
\hline
\end{tabular}

2X RIPA

$280 \mathrm{mM} \mathrm{NaCl}$

$2 \%$ Triton X-100

$0.2 \%$ Deoxycholate

2 mM PMSF
IP Wash 1

$0.1 \%$ SDS

$1 \%$ Triton X-100

2 mM EDTA

20 mM Tris, $\mathrm{pH} 8.0$

$150 \mathrm{mM} \mathrm{NaCl}$
IP Wash 2

$0.1 \%$ SDS

$1 \%$ Triton X-100

2 mM EDTA

20 mM Tris, $\mathrm{pH} 8.0$

$500 \mathrm{mM} \mathrm{NaCl}$

Dryer \& Covey - Use of chromatin immunoprecipitation (ChIP) to detect transcription factor binding to highly homologous promoters in chromatin isolated from unstimulated and activated primary human B cells

www.biologicalprocedures.com 